\title{
Bir İnfertilite Tanısından Postpartum Hikayesine
}

\author{
Gülșen AK SÖZER ${ }^{1}$
}

${ }^{1}$ Akdeniz Üniversitesi, Hemşirelik Fakültesi, Hemşirelik Bölümü, Antalya, Türkiye, gulsenaksozer@gmail.com

\begin{tabular}{|c|c|}
\hline Makale Bilgileri & ÖZ \\
\hline Makale Geçmişi & Giris: Otoetnografi, farklı yasam denevimleri olan biri tarafindan yazılmıs, otobivografik nitel arastırmadır. \\
\hline Gelis: 01.10.2020 & Amac: Yazarın gebelik öncesi infertilite tanısı ile baslavan ve doğum sonrası ilk altı av vasadı̆̆ karması ve hüzünlü \\
\hline Kabul: 27.12 .2020 & duygularını anlatmak, postpartum duygudurum değisiklikleri yasayan kadınlara dikkat cekmektir. \\
\hline Yayın: 25.04.2021 & Metod: Yazarın, gebelik öncesi infertilite tanısıyla başlayan ve doğum sonrası altı ay boyunca yaşadığı karmaşı ve \\
\hline \multirow{6}{*}{$\begin{array}{l}\text { Anahtar Kelimeler: } \\
\text { İnfertilite, } \\
\text { Otoetnografi, } \\
\text { Postpartum. }\end{array}$} & $\begin{array}{l}\text { hüzünlü duygularını anlattığı otoetnografik bir çalışmadır. } \\
\text { Olgu: Ben akademisven bir hemsirevim. Bu gercek hikavemde, doğum sonunda yașadığım karmasık duygularımı, }\end{array}$ \\
\hline & derinden hissettiğim hüzün ve ölüm düşüncelerimi dile getirdim. Gebelik, infertilite tanısı almış bir kadın için dünyanın \\
\hline & en mucizevi olayıdır. Ancak doğum sonu duygu durum değişiklikleri, bu muhteşem ritüele gölge düşürmektedir. \\
\hline & Tartışma: Otoetnografik makaleleri incelediğimde, benimle benzer duyguları yaşamış birçok kadın olduğunu gördüm. \\
\hline & $\begin{array}{l}\text { Makalelerdeki temalardan bazıları; "normal fakat acı çeken biri olarak görülme, isimsiz bir kaos yaşama, bir çıkış yolu } \\
\text { bulma mücadelesi icinde olma, günlük havattan uzaklasmıs hissetme" ifadeleridir. }\end{array}$ \\
\hline & $\begin{array}{l}\text { Sonuç ve Öneriler: Doğum sonrası kadınların en fazla desteğe ihtiyaç duyduğu dönemdir. Doğumdan sonra hem } \\
\text { fizyolojik hem psikolojik değişikliklerin olduğunu bilmeme rağmen, her şeyi unutmuştum. Bu süreç, sağllk profesyonelleri } \\
\text { tarafindan tüm gebeler ve postpartum anneler için dikkate alınması, psikososyal sağlığın yakından izlenmesi açısından } \\
\text { önemlidir. }\end{array}$ \\
\hline
\end{tabular}

From a Diagnosis of Infertility to The Story of Postpartum

\begin{tabular}{|c|c|}
\hline Article Info & ABSTRACT \\
\hline $\begin{array}{l}\text { Article History } \\
\text { Received: } 01.10 .2020 \\
\text { Accepted: } 27.12 .2020 \\
\text { Published: } 25.04 .2021\end{array}$ & $\begin{array}{l}\text { Introduction: Autoethnography is an autobiographical qualitative study written by someone with different life } \\
\text { experiences. } \\
\text { Objective: It is to explain the complicated and sad feelings of the author that started with the diagnosis of infertility before } \\
\text { pregnancy and experienced in the first six months after birth, and to draw attention to women who experienced postpartum } \\
\text { mood changes. } \\
\text { Method: It is an autoetnographic study in which the author begins with the diagnosis of infertility before pregnancy and } \\
\text { describes the complex and sad feelings she experienced during the six months after birth. } \\
\text { Phenomenon: I am an academic nurse. In this true story, I have expressed my complex feelings at the end of my childbirth, } \\
\text { my deep sorrow and my thoughts of death. Pregnancy is the world's most miraculous event for a woman diagnosed with } \\
\text { infertility. However, postpartum mood changes may undermine this magnificent ritual. } \\
\text { Discussion: When I examined autoethnographic articles, I found that there were many women who experienced similar } \\
\text { feelings with me. Some of the expressions in the articles were "being seen as a normal but painful person, experiencing an } \\
\text { anonymous chaos, struggling to find a way out, feeling alienated from everyday life". } \\
\text { Conclussion and Suggestions: Postpartum is the period when women need the most support. Although I knew that both } \\
\text { physiological and psychological changes occur after the childbirth, I had forgotten everything. This process is important } \\
\text { for all pregnant women and postpartum mothers to be taken into consideration by healthcare professionals and to closely } \\
\text { monitor psychosocial health. }\end{array}$ \\
\hline
\end{tabular}

*Bu makale, 3-6 Ekim 2019 tarihinde Konya'da yapılan 2. Uluslararas1, 3. Ulusal Doğum Sonu Bakım Kongre'sinde sözel bildiri olarak sunulmuştur.

Atıf/Citation: Ak Sözer, G. (2021). Bir infertilite tanısından postpartum hikayesine, Genel Sağllk Bilimleri Dergisi, 3(1), 8189. 


\section{GíRiş}

\section{Beni Kör Kuyularda}

"Beni kör kuyularda merdivensiz biraktın,

Denizler ortasında bak yelkensiz bıraktın,

Öylesine yıktın ki bütün inançlarımı;

Beni bensiz bıraktın; beni sensiz biraktın."

(https://blog.ufuk.io/umit-yasar-oguzcan-beni-kor-kuyularda/, 2020)

Otoetnografi, farklı yaşam deneyimleri olan biri tarafından yazılmış, otobiyografik nitel araştırmadır (Schneider, 2005). Bir yöntem olarak otoetnografi, otobiyografi ve etnografya özelliklerini birleştirir. Dolayısıyla, otoetnografi hem süreç hem de üründür (Ellis ve ark., 2011). Ellis ve Boucher (2000), otoetnografiyi, yazarın kişisel deneyimlerini ve kavramların bu deneyimler üzerindeki sosyal ve kültürel etkilerini ilişkilendirdiği bir yöntem olarak tanımlamaktadır. Otoetnografi, araştırmacının otobiyografik materyallerini birincil veriler olarak kullandığ etnografik bir sorgulamadır (Cipolletta, 2018). Otoetnografik makaleler, sağlık bakım ortamlarında çalışanları (hekimleri, hemşireleri ve ebeleri) bu yönde yönlendirebilir ve klinik verilerde olduğu gibi gerçekleri ilişkilendirme fırsatı verir (Smith ve Gallo, 2007). Otoetnografi, yaygın olarak ve kısaca, araştırmanın konusuna yönelik olarak araştırmacının, bulunduğu çevrede, içinde bulunduğu olay ya da olguda kendini araştırması olarak anlaşılmaktadır (Çelik, 2013). Sağlık ve hemşirelik alanında nispeten alışılmadık bir metodoloji olan otobiyografi, postpartum duygu durum değişiklikleri ile yaşamanın bireysel deneyimlerini aydınlatmak için kullanılmıştır. Yazar bu çalışmada gebeliğinden önce başlayıp postpartum dönemde devam eden duygu durum değişiklerine karş1 pencereden bakıp otoetnografik olarak ele almıştır. Yazar, doğum öncesinden itibaren doğum ve doğum sonunu içeren süreçte deneyimlerini anlatarak, kendisi, oğlu ve eşi açısından detaylandırmıştır. Bu çalışmanın amacı; yazarın gebelik öncesi infertilite tanısıyla başlayıp, doğum sonu ilk altı ay yaşadığı karmaşık ve hazin duygularını anlatmak ve postpartum duygu durum değişikliği yaşayan kadınlara dikkat çekmektir.

\section{OLGU}

Ben Doğum ve Kadın Sağlığı alanında çalışan Akademisyen bir hemşireyim. Bu gerçek hikayemde, gebelik ve doğum sonunda yaşadığım karmaşık duygularımı, derinden hissettiğim hüzün ve ölüm düşüncelerimi dile getirdim. İnsan yaşamında evlilik, gebelik, annelik gibi dönemler birer geçiş sürecidir. Bu geçiş süreçleri bazen bir kriz durumuna dönüşebilir. Bu otoetnografik çalışmada yaşadıklarımı "infertilite tanısından sonra gebelik, doğum sonu duygu durum değişiklikleri, yardım arama ve bir çıkış yolu bulma” olarak temalandırdım.

\section{Infertilite Tanısından Sonra Gebelik}

İnfertil olmak, birçok kadında, düşük benlik saygısı, damgalanma, sosyal izolasyon, anksiyete, depresyon, boyun eğitici ve kaderci tutum gibi duygulara neden olabilir (Tabong ve Adongo, 2013; Kırca ve Pasinlioğlu, 2013; Hasanpoor-Azghdy ve ark., 2014). Bununla birlikte, infertilite tanısından sonra gebe kalan kadınların bazıları için gebe kalmasıyla birlikte her şey yoluna girmemiştir. Hatta durum daha da karmaşı hale gelmiştir. Kadınlar içinde bulundukları durumu, "infertil olarak kalan kimlik, anneliği gerçeküstü olarak algılamak, annelik rolü için hazırlıksız hissetmek, anne olduğu için şükretmek, mükemmel anne olmaya ihtiyaç duymak, sansürlenmiş hissetmek, yetersiz hissetmek, kayıp ve çaresiz hissetmek, beklenen ve gerçek annelik arasında tutarsızlı, infertilitenin gebelik ve anneliği gölgelemesi, gebeliğin infertiliteden ayrışmaya yol açması, hem infertilite hem gebelik yaşamının birlikte var olması" gibi ifadelerle dile getirmiştir (Ladores ve Aroian, 2015; HaCohen ve ark., 2018). İnfertilite tanısından sonra gebeliğe geçiş yapma zor olabilir. Bu zorluk anneliğe uyum yeteneğinin azalması ve postpartum depresif belirtilerin daha fazla olmasına yol açabilir. İnfertilite tanısı ve tedavisi nedeniyle uzun süre bekleyiş, anneleri hem fiziksel hem de ruhsal olarak yorgun düşürmüş olabilir. (Boz ve ark., 2018).

Gebelik, infertilite tanısı almış bir kadın için dünyanın en mucizevi olayıdır. Bebeğin doğumu ise bunu mutlulukla taçlandıran en tepe noktadır. Ancak doğum sonu duygu durum değişiklikleri, bu muhteşem ritüele gölge düşürmektedir. Evlenen hiçbir bireyin aklına infertilite düşüncesi gelmezken, infertilite ile yüzleşip sonrasında 
gebe kalan bir kadının postpartum depresyon yaşaması şımarıklık gibi gelir çoğu insana. Ben infertilite tanısı alan biri olarak gebe kalıp, sağllklı bir çocuk dünyaya getirdiğimde, dünyanın tozpembe olacağını düşündüm. Yaşadıklarımdan şunu anladım; "damdan düşenin halinden damdan düşen anlarmış" özdeyişi gibi insan yaşamadan tam olarak bir insanın ne yaşadığını, anlayamıyormuş. Yaşayarak anlamak benim serüvenimde çok sancılı ve çok acıtıcı oldu. Zor bir dört ylllı infertilite süreci yaşarken, üzerine bir de premenopoz tanisının eklenmesiyle biten ümitler, 42 yaşımda sürpriz bir gebelikle sonuçlandı. Sürpriz dedim, ama eşim ve benim içimizde umutlarımı bitmemişti. Hem de oğlumuz olacaktı. Belki de ikiz. Bir oğlum olmuştu. Bu gerçekten mucizeydi. Oğlum benim en güzel, en büyük, en değerli mucizemdi. 43 yaşımda sezaryen ile doğurduğum oğluma kavuştum. Aslında her şey istediğim gibiydi.

\section{Doğum Sonu Duygu Durum Değişiklikleri}

Duygusal sorunların, bir kadının hayatının diğer dönemlerine kıyasla gebelik ve doğum sonrasında daha sık ortaya çıktığı gözlemlenmiştir (Maliszewska ve ark., 2016). Bir bebeğin doğumu, karmaşık duygulara yol açabilir. Yeni doğum yapan annelerin çoğu, doğumdan sonraki iki gün ile iki hafta arasında annelik hüznü olarak bilinen anksiyete, korku, endişe, ağlama krizleri, uykusuzluk gibi ruhsal değişiklikler yaşar (Mayo clinic, 2020). Doğum sonu hüzün, doğumdan sonra ilk günlerde görülen hafif ve kendi kendini sınırlayan bir bozukluk olarak algılanır. Ancak, doğum sonrası depresyon veya anksiyete bozuklukları için önemli bir risk faktörü oluşturmaktadır (Reck ve ark., 2009; Maliszewska ve ark., 2016). Doğum sonu depresyon, doğum sonu hüzünden daha ciddidir. Annenin normal aktivitelerini, aile ilişkilerini, bakım kapasitesini ve bebeğine bağlanmasını olumsuz etkiler (McGrray ve ark., 2009). Doğum sonrası ruhsal bozukluk riskini etkileyen psikolojik nedenler arasında yenidoğanın davranışının anlaşılamaması, hayal edilenin aksine anneliğin gerçek resmi, karamsarlık, düşük benlik saygısı ve yüksek düzeyde nevrotiklik yer alır. Bununla birlikte annenin duygusal durumunu, sosyal destek yetersizliği, ailesel problem, eş ile çatışma yaşama, gebelikte stresli yaşam olayları, tek ebeveynli aile veya birlikte yaşama, planlanmamış veya istenmeyen gebelik ve ayrıca riskli gebelik de olumsuz etkileyebilir (Maliszewska ve ark., 2016).

Her şeyin istediğim gibi olmasına ră̆men, gebeliğimde başlayan içimde istediğim gibi gitmeyen, bir şeyler oluyordu. Korkuyordum, panik oluyordum, uyuyamıyordum, çok mutsuzdum. İçimde derinlerden gelen, acı ile karışık bir hüzün vardı. Karanlık, kör bir kuyuya düşmüşü̈m ve çıkabilmek için sürekli bir ışık, bir merdiven arıyordum. Yemek yiyemiyor, su içemiyordum. Lokmalar boğazımda dü̆̈̈̈mleniyordu. Oysa iyi olmam, iyi beslenmem ve bebeğim için süt yapmam gerekiyordu. Bunu bildiğim için de boğazımı yara yara yemek yiyor ve su içiyordum. Gel gelelim ne istenilen düzeyde sütüm oluyordu ne de bebeğim kilo alıyordu. Meme başım çatlamış ve mastit olmuştum. Üstelik hızla gebelik öncesi kiloma düşmüşüm. Okuldan hocalarım gelmişti. Beni banyoya sokup memelerimi boşalttılar (Durumla ilgili hiç yorumda bulunmadılar. Kendi doğum sonu hikayelerinden hiç bahsetmediler). Hem tıbbi hem de geleneksel birtakım uygulamaları yapmama rağmen dört ay meme başı çatlaklarım devam etti. Doğum sonu altı hafta devam eden vajinal kanamalarım oldu. Cinsel ilişki sırasında ağrım oluyordu. Bebeğimin altı pişik oluyor ve çok az kilo alıyordu. Doğumdan birkaç gün sonra ziyaretime gelen bir arkadaşım "sende deli düve sendromu görüyorum" demişti. Deli düve, şaşkındır. Ben sadece deli düve değildim. Kendimi yetersiz, başarısız ve çaresiz hissediyordum. Ne aynada kendime bakıyor, ne de bebeğimi benim bebeğimmiş gibi hissediyordum. Ama bebeğimin bakımını eksiksiz yerine getirdiğimi sanıyordum. Ağlayınca emziriyor, altını kirletince değiştiriyor, banyosunu yaptırıyordum. Bir de geceleri çok sık uyanıp ăgladı̆̆ için, kolik olduğunu düşünüyor ve sürekli gazını çıkarmaya çalışıyordum. Onun dışında hiçbir şey yapamamış olduğumu sonradan anladım. Bebeğimi şimdi sevdiğim gibi sevgi ve şefkat dolu sevdiğimi hiç hatırlamıyorum. Sadece "ben öleceğim ve bebeğim yalnı kalacak” diye derin acı çekiyordum. Şimdi o günlerin telafisi olmadığını biliyorum. Ama oğlumdan uzakta kalıp, ayrı geçirdiğim zaman onun hayatından çaldığımı düşünüyorum.

Her şeyin farkında olan, ama bunu ifade edemeyen, sürekli kendi ölümünü düşünen, kendini kendi cenaze töreninde hayal eden, arkasında minik yavrusunu bırakmak istemeyen, oğlum 2 yaşında, 4 yaşında, 20 yaşında olduğunda ölmek için Allah ile pazarlık yapan, yalvaran bir anneydim. Öleceğimi sanıyordum. Erken ölmekten çok korkuyor ve ölümü düşünmekten derin bir hüzün ve acı duyuyordum. Bu derin hüzün ve acı dayanılmaz bir durumdu. Eskiden ă̆lamadan izlediğim çok az Türk filmi olmasına rağmen, ă̆lamak istiyordum ama ă̆layamıyordum. Ŏglumu kimi zaman babama, anneme, kimi zaman kardeşime, kimi zaman ablama, kimi zaman 
amcasına, kimi zaman da Avustralya'daki halasına emanet etmeyi hayal ediyordum. Nedense babasına/eşime emanet edemiyordum. Sanki ben ölürsem hemen evlenecekmiş gibi bir duyguya kapıliyordum. Eşimi sadece evin gereksinimlerini karşılayan, ben yemek yerken oğluma göz kulak olan biri olarak görüyordum. Eşimden uzaklaşmış ve onu da kendime uzak hissediyordum. Eşimle tek ortak şeyimizin oğlumuz olduğunu düşünüyordum. Oğlumuz olmasa evlilik ilişkimiz orada bitecekti sanki. Ne öncesi ne de sonrası hiç düşünmediğim, benden başka bir kadının bile olabileceğini düşündüm. Buna kısmen hasetlenmiş olsam da doğrusu çok üstünde bile duramadım. Çünkü ben eşimden uzak, çok başka bir dünyada yaşıyordum. Eşimle içinde yaşadı̆̆ım duygusal durumumu konuşamıyordum. Oysa eşim, doğumdan sonra beni desteklemek için on gün babalı izninin ardından otuz gün senelik izin almış ve hep bizimle olmuştu. Ancak onun da biraz kaygılı ve mutsuz olduğunu düşünüyordum (Eşim ile bu durumu o zamanlar konuşamadım. Sonra da hiç konuşmadık). Minik oğlum ise, sürekli kucağımda ve emzik yerine mememi emiyordu. Günde on iki kere kaka yapıyor ve çok az kilo alyyordu. Gece saat 01.00 da başlayan kolik nöbetleri sabah saat 06.00'a kadar sürüyordu. Bebeğim de çok huzursuz ve mutsuzdu. Benim duygularımın tamamı oğluma geçiyordu. Beni hissediyordu. Günler geçmek bilmiyordu. Gündüzler zaten uzundu, gecelerde bir o kadar uzuyordu. Geceleri ne yatağımda ne de başka yerde uyuyamıyordum. Zaman durmuştu. Su gibi akmıyordu. Göl gibi durgundu. Bense görünmeyen bir akıntıya kapılmıştım. Boğuluyordum! Nefes almakta zorlanıyordum. Nefes alabilmek için oğlum yirmi günlük iken pusete koyarak, elimde poşet taşır gibi pazara gidiyordum. Sokak aralarında dolaşıyordum. Evin içinde oturamıyor ve sürekli balkonda oturuyordum. Oysa, doğum yaptı̆̆ım andan itibaren, uzak yakın bütün arkadaşlarım, dostlarım, komşularım, ailem ziyaretime geliyor, gelemeyenler telefonla arayıp, tebrik ediyordu. Önce doğum yaptı̆̆ım hastane dolup taşmıştı, sonra da evimiz. Komşularım hayranlıkla ziyaretime gelenleri izliyordu. Ama ben hala derin bir hüzün içinde gelip gidenleri izliyordum. Gelenler gittikten sonra yine karanlı köşeme çekilip ölümü düşünüyor ve oğlumu emziriyordum. Ziyaretime gelenler biraz oğlumu sevip, bana birkaç emzirme önerisinde bulunup, "seni meşgul etmeyelim" deyip gidiyorlardl. Benim kafam zaten meşguldü. Daha fazla meşgul edemezlerdi. Beni anlamadıklarını düşünüyordum. Ben de anlatamıyordum.

\section{Yardım Arama ve Çıkış Yolu Bulma}

Doğum sonu dönemde, ruhsal durum bozukluğu olan kadınların yardım arama davranışlarının yetersiz olduğu belirtilmektedir. Yardım aramaya engel olan durumlara, prenatal dönemde eğitim almamış olmak, düşük eğitim düzeyi, düşük gelir düzeyi, işsizlik, multipar olmak, genç anne olmak, duygularını açığa vuramamak, gebeliğinde ve gebelik öncesi dönemde depresyon öyküsünün olması, emosyonel şiddet ve distres (Dennis ve Chung-Lee, 2006; McGarry ve ark., 2009), akıl hastalığı tanısı nedeniyle duyguların hafife alınması, utanma ve damgalanma düşüncesi, profesyonel yardım almak için kime başvuracaklarını bilememeleri, sağlı profesyonelleri tarafından durumlarının fark edilmemesi, önerilecek ilaç tedavisinin emzirmeye engel olacağı düşüncesi, işsizlik, gebelikte tıbbi komplikasyon, zaman yetersizliği ve korku gibi nedenler olduğu ortaya çıkmıştır (Goodman, 2009; Foulkes, 2011; Fonseca ve ark., 2015). Postpartum depresyon ile yardım arama davranışları arasında negatif bir ilişki vardır. Yardım arama davranışı göstermeyen annelerin, depresyonları daha kötü düzeyde bulunmuştur (Almutairi ve ark., 2017). Yardım arama davranışı eksikliği, postpartum süreçte anne ve bebek açısından olumsuz sonuçlara neden olabilir (Beck, 2008; Grissette ve ark., 2018).

Önceleri yardım almam gerektiğini düşünemiyordum. Birkaç hafta sonra, yardım almam gerektiğini düşündüm. Ancak bunun için bile bir plan yapamadım. Birisinin bana yol göstermesi gerekiyordu. Psikiyatri hemşiresi olan bir sınıf arkadaşımı aradım. Durumumu anlatmaya çalıştım. Tam olarak anlatamadım. Bana bir psikiyatri doktoru önerdi. Doktoru ben taniyordum. Psikiyatri doktoruna telefon ettim. Telefonda özel hastanede çalıştı̆̆ııı ve artık üniversite hastanesinde hasta bakmadı̆̆ını söyledi. Buna üzüldüm. Zaten çok kırılgandım. Doktora gitsem de ilaç önereceğini ve ben emzirdiğim için, ilaç kullanmamam gerektiğini düşünüyordum. Bir yandan buna memnun oldum. O anda önemli bir karar aldım. Ben bu durumumla baş etmeyi becereceğim dedim. Yine güvendiğim ve bana güvendiğini bildiğim, yüksek lisans danışman hocamı aradım. Kısmen durumumdan bahsettim. Kendimi çok anlatamıyordum. Ama hocam beni anladı. Bana "sen güçlüsün, başarırsın" dedi. Bu söz bana kendimi iyi hissettirdi. Kendimi iyi olacağıma ve bebeğime iyi bakacağıma inandırdı. Gücümün farkına vardırması bakımından çok önemliydi. Hocam aynı zamanda bana "Siyah Sütü" okumamı tavsiye etti. Kitabı aldım, ama okuyamadım. Hala da okumadım... 
Uzaktan telefon ile yaptı̆̆ım bu iki görüşme ve aldı̆̆ım karardan sonra şafak sökmeye başladı. Penceremden az da olsa ışık sızmaya başladı. Daha rahat nefes alıyordum. Geceleri uyuyabiliyordum. Oğlumu sevmeyi ögrenmeye başlamıştım. Günler haftaları, haftalar ayları kovaladı. Oğlum dört aylık oldu. Çok güzel bir bebek olduğunu yeni fark ettim. Annem ve kardeşim ziyaretime gelip gittikten sonra oğlum arkalarından ă̆ladi. Ben düşündüm ki, oğlum benimle mutlu değildi ve onlar gittiği için üzülmüştü. Kendimi suçladım. Ama yine kendime döndüm ve "iyi olacağım" dedim. Ben iyi olursam bebeğim de iyi olacaktı. Artık evden çıkıp komşulara, arkadaşlarıma ve çalıştığım yere gitmeye başladım. Kendim için alışveriş yapar oldum. İşe dönmeden önce oğlum için bakıcı bulma girişimlerinde bulundum. Oğlum altı aylık oldu. Ek besinleri hazırlamaya başladım. Artık içimdeki acı, hüzün ve sıkıntı azalmış, kendimi daha az kendi cenaze törenimde ve oğlumu arkamdan ă̆larken hayal ediyordum. Artık oğlumla beraber bir yirmi yıl beraberlik düşünüyor, bazen de üniversiteden bile mezun ediyordum. Ŏgluma bağlanmam tamamlanmıştı. Şimdi oğlum ilkokul dördüncü sınıfta okuyor. Ben ilk kez o günleri düşündüğümde içimdeki acının azaldığını hissettim ve yaşadıklarımı ağlamadan yazabildim. Hayat çok güzeldi! "Oğlum hayat, hayat oğlumdu”. Artık eşim ve oğlum ile beraber seksen yaşına kadar săglıkl yaşayacağım ve torunlarıma bakabileceğim yılları hayal ve umut edebiliyorum. Ama bu yaşadiğım derin hüzün ve ölüm duygusunu, telafisi mümkün olmayan kayıp zamanları yaşamamış olmayı çok isterdim.

\section{TARTIŞMA}

Sağlıkla ilgili otoetnografik çalışmalarda postpartum depresyon çok sık vurgulanmaktadır (Hall, 2006; Gao ve ark., 2010; Ladores, 2014). Etnografik ve otoetnografik çalışmaları incelediğimde, benimle benzer duyguları yaşamış birçok kadın olduğunu gördüm. Üstelik bu çalışmalardan birindeki öykü benim gibi sağlık profesyoneli bir hekim idi (Frankhouser ve Defenbaugh, 2017). Ladores ve Aroian (2015), daha önce infertilite öyküsü olan annelerin deneyimlerini infertilitenin "kalıcı kimlik olduğunu ve annelik armağanı için minnettar olmak" temaları altında açıklamıştır. Bazı kadınlar, anneliği gerçeküstü olarak algılayıp, bebeklerini kucaklarına aldıklarında şok olduklarını, mükemmel bir anne olmak zorunda olduklarını, bazı kadınların da postpartum depresyon yaşadıklarını, daha önce infertilite tanısı alan annelerin, postpartum depresyon tanısı alıp almadığını sorguladıklarını, uykusuz, yorgun, mutsuz, olduklarını, bu durumu kocası ile paylaştığında kendisini anlamadığını, bu nedenle duygularını kendine sakladığını ve yardım arama çabasından vazgeçtiğini belirtmişlerdir (Ladores ve Aroian, 2015). Dahl ve ark. (2017), çalışmasında, normal fakat acı çeken biri olarak görülme, gerçeklikten uzaklaşma, isimsiz bir kaos yaşama ve bir çıkış yolu bulma mücadelesi içinde olduklarını belirtmişlerdir. Coates ve ark. (2014), çalışmasında kadınların bazıları "günlük hayattan uzaklaşmış hissettiklerini, hayatlarının umdukları gibi başlamadığını, bebeğine bağlanamadığını ve başka birinin bebeğini tutuyormuş gibi hissettiklerini” ifade etmişledir. Hall (2006)'nın, çalışmasındaki temalardan biri, postpartum dönemde kadınların kendilerini "kapana kısılmış" hissetmesidir. Frankhouser ve Defenbaugh (2017), otoetnografik çalışmasında ise yetersizlik, suçluluk, yardım istemekten kaçınma ve utanç duyma temaları ortaya çıkmıştır. Chan ve ark. (2002), çalışmasında postpartum dönemde kadınlar, duruma hapsolduklarını, bebekle ilgili ambivalan duygular yaşadıklarını, kocalarından yardım alamadıklarını, kontrol ve gücün eşlerinin ailesinde olduğunu ifade etmişlerdir. Gao ve ark. (2010), çalışmasında doğum sonu dönemde anneler, tükenmişlik hissi, (fiziksel ve duygusal tükenme), başarısızlık duygusu (yetersiz ve kusursuz anne, negatif vücut imajı), geleneksel ve modern uygulamalar arasındaki uyumsuzluk (ikilem, kayın valide ile çatışmalar, cinsiyet tercihi, beklentiler ve gerçeklik arasındaki uçurum) temaları yer almaktadır.

Doğum sonu duygu durum değişiklikleri, postpartum hüzünden postpartum psikoza kadar ilerleyebilmektedir. Postpartum hüzün en hafif düzeydeki duygu durum değişikliği olsa da anne ile bebeğin birbirlerine bağlanmaya başlandıkları dönemde olması açısından çok önemlidir. Annedeki doğum sonu duygu durum değişiklikleri, bebeğini istemeden ihmal etmesine, emzirmenin başlayamamasına veya kesintiye uğramasına, fiziksel ve duygusal yakınlığın yokluğuna neden olabilir (Frankhouser ve Defenbaugh, 2017). Yapılan bir çalışmada, çocukluk döneminde fiziksel (düşük kilo ve boy), emosyonel ve bilişsel problemlere (konuşma geriliği), adölesan dönemde ise klinik depresyon riskinde artışa neden olabileceği belirtilmiştir. Postnatal depresyon ve bozukluklarının, 16 yaşına kadar olan çocuğun dışa vuruk davranışlarında, özellikle hiperaktivite ile ilişkili probleme neden olduğu belirtilmektedir (Stein ve ark., 2014). Coates ve ark. (2014), kalitatif çalı̧̧masında, postnatal distresin, annelerin bebekleriyle birlikte yeni yaşamlarını istenmeyen bir başlangıç olarak algılamalarına 
yol açtığını, doğum ve emzirme güçlükleri, yeni durumun şoku, anneliğe uyum ve sosyal desteğin önemini vurgulamışlardır. Annede ise derin hüzün, bebeği ve kendi bakımı ile ilgili endişe, anksiyete, çaresizlik duygusu, uykusuzluk, yorgunluk, unutkanlık, iştahsızlık, ağlama nöbetleri ve enerji azlığı, suçluluk, değersizlik, karamsarlık duygularına neden olabilir (Erdem ve Bez., 2009; Yüksekol ve ark., 2014). Görüldüğü üzere, postpartum duygu durum değişiklikleri hem anneyi hem de bebeğini olumsuz yönde etkilemektedir. Anne ile bebeğin yaşam coşkusuna gölge düşürmektedir.

Annedeki postpartum duygu durum değişikliklerinin, eşleri de olumsuz etkilediği belirtilmektedir. Erkeklerdeki postpartum depresyonun, eşlerinin postpartum depresyonu ile ilişkili olabileceği vurgulanmaktadır (Scarff, 2019). Yapılan bir çalışmaya göre; postpartum psikiyatrik bozukluk yaşayan kadınların eşlerinin yaşamlarında büyük bir değişiklik olduğu belirlenmiştir. Bu eşler, korku, şaşkınlık ve öfke ifade etmişler; ayrıca eşleri için son derece endişeli olup ve rahatsızlı̆̆ı üstesinden gelmeye yardımcı olamayacaklarını hissetmiştir. Erkeklerin çoğu, ilişkiyi ve aileyi bir arada tutmak için fedakarlık yaptığını anlatmıştır. Sorunlar zamanla düzelse de, daha önce tanıdıkları kişiden çok farklı görünen bir kadınla, belirsiz bir gelecekle karşı karşıya kalmıştır. Erkeklerin çoğu olgunlaştığını ve öz saygılarının arttığını belirtirken, ancak bazıları için sonuç boşanma, velayet anlaşmazlıkları ve yalnızlık olmuştur (Engqvist ve Nilson, 2011). Postpartum depresyonun önlenmesinde eşlerin desteği önemli bir faktördür (Misri ve ark., 2000; Zörer ve ark., 2019). Eş desteği ile postpartum depresyon arasında önemli bir ilişki olduğu ve eş desteğinin yüksek olmasının doğum sonu depresyonu önleyebileceği belirtilmektedir (Armini ve Tristiana, 2017). Bu nedenle gebelikte ve postpartum dönemde eşlerin birlikte ele alınması göz ardı edilmemelidir.

\section{SONUÇ ve ÖNERÍLER}

Doğum sonu dönemim oldukça karmaşık, emosyonel olarak çok ağır ve fiziksel olarak da çok yorucu bir süreç olarak geçti. Geç evlenmiş, geç evlendiği için pişmanlık duyan, dört yıl infertilite tanısı almış, ileri yaş, primipar, sezaryen ile doğum yapmış, kolik olan bebeğe sahip bir anne idim. Yaşama sevincim kaybolmuş, uyuyamıyor, sürekli yorgunluk hissediyor, enerji azlığı, odaklanma güçlüğü çekiyordum. Yetersizlik, suçluluk, mutsuzluk ve umutsuzluk duyguları içinde, sürekli ölümü düşünüyordum. Kendimi ölümün kıyısında, kendi cenaze törenimde düşünüyor, acılar içinde kıvranıyordum. Bu tam dört ay sürdü. Hayatımın en uzun dört ayıydı.

Doğum sonrası kadınların en fazla desteğe ihtiyaç duyduğu dönemdir. Doğumdan sonra hem fizyolojik hem psikolojik değişikliklerin olduğunu bilmeme rağmen, her şeyi unutmuştum. Ümit Yaşar Oğuzcan'ın (https://blog.ufuk.io/umit-yasar-oguzcan-beni-kor-kuyularda/), ünlü şiirinin "Beni kör kuyularda merdivensiz bıraktın" mısrası bu süreçteki doğum sonu anneleri çok güzel tanımlamıştır. Belki de, hemşire arkadaşlarım, hocalarım ve ailemden destek almasaydım ölümün kıyısında dolaşırken kendime ve bebeğime daha fazla zarar verecektim. Bu sürecin, sağlık profesyonelleri tarafından tüm gebeler ve postpartum anneler için dikkate alınması, psikososyal sağlı̆̆ın yakından izlenmesi açısından önemlidir.

\section{Finansal destek}

Finansal destek alınmamıştır.

\section{Çıkar Çatışması}

Herhangi bir çıkar çatışması yoktur.

Yazar Katkıları:Tasarım/Design: G.A.S.; Veri Toplama veya Veri Girişi Yapma/Data Collection or Processing: G.A.S.; Analiz ve Yorum/Analysis or Interpretation: G.A.S.; Literatür Tarama/Literature Search: G.A.S.; Yazma/Writing: G.A.S. 


\section{KAYNAKÇA}

Almutairi, A.F., Salam, M., Alanazi, S., Alweldawi, M., Alsomali, N., \& Alotaibi, N. (2017). Impact of help-seeking behavior and partner support on postpartum depression among Saudi women. Neuropsychiatric Disease and Treatment, 13, 19291936. https://dx.doi.org/10.2147\%2FNDT.S135680

Armini N.K.A., \& Tristiana, R.D. (2017). Husband's support is needed to prevent postpartum depression. Advances in Health Sciences Research, 3, 4-7. -8th International Nursing Conference (INC 2017). https://dx.doi.org/10.2991/inc-17.2017.7

Beck, C.T. (2008). State of the science on postpartum depression, part 2. The American Journal of Maternal/Child Nursing, 33(3), 151-156. doi: 10.1097/01.NMC.0000318349.70364.1c

Boz, İ., Özçetin, E., \& Gamze Teskereci. (2018). İnfertilitede Anne Olma: Kuramsal Bir Analiz. Psikiyatride Güncel Yaklaşımlar-Current Approaches in Psychiatry, 10(4), 506-521. doi:10.18863/pgy.382342

Chan, S. W. C., Levy, V., Chung, T. K., \& Lee, D. (2002). A qualitative study of the experiences of a group of hong kong chinese women diagnosed with postnatal depression. Journal of Advanced Nursing, 39(6), 571-579. https://doi.org/10.1046/j.1365-2648.2002.02326.x

Cipolletta, S. (2018). When childbirth becomes a tragedy: What is the role of hospital organization? Journal of health psychology, 23(7), 971-981. https://doi.org/10.1177\%2F1359105316660182

Coates, R., Ayers, S., \& de Visser, R. (2014). Women's experiences of postnatal distress: a qualitative study. BMC pregnancy and childbirth, 14(359), 1-14. http://www.biomedcentral.com/1471-2393/14/359

Çelik, H. (2013). Kültür ve kişisel deneyim: bir araştırma yöntemi olarak otoetnografi [Culture and personal experience: autoethnography as a Research method]. İstanbul Journal of Social Sciences, 6, 1-14 ISSN: 2147-3390. http://www.istjss.org/resim/2013_winter_6_1.pdf

Dahl, B., Hermansen, M., \& Severinsson, E. (2017). Lost in a nameless chaos-women's experiences of postpartum depression. A meta-ethnographic study. Open Journal of Nursin, 7, 962-977. https://doi.org/10.4236/ojn.2017.78071

Dennis, C-L., \& Chung-Lee, L. (2006). Postpartum depression helpseeking barriers and maternal treatment preferences: A qualitative systematic review. Birth, 33(4), 323-31. doi: 10.1111/j.1523-536X.2006.00130.x.

Ellis, C., \& Bochner, A. (2000). Autoethnography, personal narrative, reflexivity: Researcher as Subject. In N. K. Denzin \& Y. S. Lincoln (Eds.), The handbook of qualitative researc. (2nd ed., pp. 733-768). Thousand Oaks, California 91320, Sage Publication. https://www.amazon.ca/Handbook-Qualitative-Research-Norman-Denzin/dp/0761915125

Ellis, C., Adams, T. E., \& Bochner, A. P. (2011). Autoethnography: an overview. Historical social research/Historische sozialforschung, 12 (1), 273-290. http://www.qualitative-research.net/index.php/fqs

Engqvist, I., \& Nilsson, K. (2011). Men's experience of their partners' postpartum psychiatric disorders: narratives from the internet. Mental Health in Family Medicine, 8, 137-46. https://www.ncbi.nlm.nih.gov/pmc/articles/PMC3314270/

Erdem, Ö., \& Bez, Y. (2009). Doğum sonrası hüzün ve doğum sonrası depresyon [Postpartum blues and postpartum depression]. Konuralp Tip Dergisi [Journal of Konuralp Medical], 1(1), 32-37. https://dergipark.org.tr/en/pub/ktd/issue/10311/126499

Fonseca, A., Gorayeb, R., \& Canavarro, M.C. (2015). Women's help-seeking behaviours for depressive symptoms during the perinatal period: Socio-demographic and clinical correlates and perceived barriers to seeking professional help. Midwifery, 31, 1177-1185. https://doi.org/10.1016/j.midw.2015.09.002

Foulkes, M. (2011). Enablers and barriers to seeking help for a postpartum mood disorder. J. Obstet. Gynecol. Neonatal. Nurs, 40, 450-457. https://doi.org/10.1111/j.1552-6909.2011.01264.x

Frankhouser, T. L., \& Defenbaugh, N. L. (2017). An autoethnographic examination of postpartum depression. The Annals of Family Medicine, 15(6), 540-545. https://doi.org/10.1370/afm.2107.

Gao, L.L., Chan, S.W., You, L., \& Li, X. (2010). Experiences of postpartum depression among first-time mothers in Mainland China. J Adv Nurs, 66(2), 303-312. https://doi.org/10.1111/j.1365-2648.2009.05169.x

Goodman, J. H. (2009). Women's attitudes, preferences, and perceived barriers to treatment for perinatal depression. Birth, 36(1), 60-69. https://doi.org/10.1111/j.1523-536X.2008.00296.X

Grissette, B.G., Spratling,R., \& Aycock, D.M. (2018). Barriers to Help-Seeking Behavior Among Women With Postpartum Depression. Journal of Obstetric, Gynecologic \& Neonatal Nursing, $47(6), \quad 812-819$. https://doi.org/10.1016/j.jogn.2018.09.006

HaCohen, N., Amir, D., \& Wiseman, H. (2018). Women's narratives of crisis and change: Transitioning from infertility to pregnancy. J Health Psychol, 23, 720-730. https://doi.org/10.1177\%2F1359105316652465

Hall, P. (2006). Mothers' experiences of postnatal depression: an interpretative phenomenological analysis. Community Practitioner, 79(8), 256-260. http://europepmc.org/article/med/16922035

Hasanpoor-Azghdy, S.B., Simbar, M., \& Vedadhir, A. (2014). The emotional-psychological consequences of infertility among infertile women seeking treatment: Results of a qualitative study. Iran Journal of Reproductive Medicine, 12, 131-138. https://www.ncbi.nlm.nih.gov/pmc/articles/PMC4009564/pdf/ijrm-12-131.pdf

https://blog.ufuk.io/umit-yasar-oguzcan-beni-kor-kuyularda/. Beni Kör Kuyularda Merdivensiz Bıraktın. Erişim tarihi, 
24.09.2020

Kırca, N., \& Pasinlioğlu T. (2013). İnfertilite Tedavisinde Karşılaşılan Psikososyal Sorunlar. Psikiyatride Güncel YaklaşımlarCurrent Approaches in Psychiatry, 5(2), 162-178. doi:10.5455/cap.20130511

Ladores, S. (2014). Postpartum depression in previously infertile mothers: a meta-ethnography. Journal of Ethnographic \& $\begin{array}{llllll}\text { Qualitative } & \text { Research, } & 9, & 121-160 . & \text { ISSN: } & 1935-330\end{array}$ http://eds.b.ebscohost.com/eds/pdfviewer/pdfviewer?vid=0\&sid=f514d90a-cf7d-4725-8bc1-2755d1fe27e4\%40pdc-v$\underline{\text { sessmgr02 }}$

Ladores, S., \& Aroian, K. (2015). The early postpartum experience of previously infertile mothers, JOGNN, 44, $370-379$. https://doi.org/10.1111/1552-6909.12576

Mayo clinic. (2020). https://www.mayoclinic.org/diseases-conditions/postpartum-depression/symptoms-causes/syc-20376617 Erişim tarihi, 01.12.2020.

Maliszewska, M., Świątkowska-Freund, M., Bidzan, M., \& Preis, K. (2016). Relationship, social support, and personality as psychosocial determinants of the risk for postpartum blues. Ginekologia Polska, 87(6), 442-447. https://doi.org/10.5603/gp.2016.0094

McGarry, J., Kim, H., Sheng, X., Egger, M., \& Baksh, L. (2009). Postpartum depression and help-seeking behavior. Journal of Midwifery \& Women's Health, 54(1), 50-56. https://doi.org/10.1016/j.jmwh.2008.07.003

Misri, S., Kostaras, X., Fox, D., \& Kostaras, D. (2000). The Impact of Partner Support in the Treatment of Postpartum Depression. Can J Psychiatry, 45, 554-558. https://doi.org/10.1177\%2F070674370004500607

Reck, C., Stehle, E., Reinig, K., \& Mundt, C. (2009). Maternity blues as a predictor of DSM-IV depression and anxiety disorders in the first three months postpartum. Journal of Affective Disorders, 113, 77-87. https://doi.org/10.1016/j.jad.2008.05.003

Scarff, J.R. (2019). Postpartum Depression in Men. Innov Clin Neurosci, 16(5-6), 11-14. https://www.ncbi.nlm.nih.gov/pmc/articles/PMC6659987/pdf/icns_16_5-6_11.pdf

Schneider, B. (2005). Mothers talk about their children with schizophrenia: a performance autoethnography. Journal of Psychiatric and Mental Health Nursing, 12(3), 333-340. https://doi.org/10.1111/j.1365-2850.2005.00844.x

Smith, C.A., \& Gallo, A. M. (2007). Applications of performance ethnography in nursing. Qualitative Health Research, 17(4), 521-528. https://doi.org/10.1177\%2F1049732306298755

Stein, A., Pearson, R.M., Goodman, S.H., Rapa, E., Rahman, A., McCallum, M., \& Pariante, C.M. (2014). Effects of perinatal mental disorders on the fetus and child. The Lancet, 384(9956), 1800-1819. https://doi.org/10.1016/S0140-6736(14)61277$\underline{0}$

Tabong, P.T., \& Adongo, P.B. (2013). Infertility and childlessness: A qualitative study of the experiences of infertile couples in Northern Ghana. BMC Pregnancy and Childbirth, 13, 1-10. https://bmcpregnancychildbirth.biomedcentral.com/track/pdf/10.1186/1471-2393-13-72.pdf

Yüksekol, Ö.D., Arguvanlı S.Ç., \& Başer, M. (2014). Annelik Hüznü ve Hemşirelik [Postpartum Blues and Nursing]. Erciyes Üniversitesi Sağlık Bilimleri Fakültesi Dergisi [Eeciyes University Journal of Faculty of Health Science], 2(1), 56-61. https://dergipark.org.tr/en/download/article-file/66933

Zörer, P.B., Akbulut, S.T., \& Dirik, G. (2019). Role of attachment patterns and partner support in postpartum depression. Psikiyatride Güncel Yaklaşımlar [Current Approaches in Psychiatry], 11(2), 154-166. doi:10.18863/pgy.387288 


\section{EXTENDED ABSTRACT}

Introduction: Autoethnography is an autobiographical qualitative study written by someone with different life experiences. Ellis and Boucher, describe autoethnography as a method by which the author associates his/her own personal experiences with the social and cultural effects of concepts on these experiences. Autobiography, a relatively unconventional methodology in the field of health and nursing, has been used to illuminate individual experiences of living with postpartum mood changes.

Objective: It is to explain the complicated and sad feelings of the author that started with the diagnosis of infertility before pregnancy and experienced in the first six months after birth, and to draw attention to women who experienced postpartum mood changes.

Materials and Methods: It is an auto-etnographic study in which the author begins with the diagnosis of infertility before pregnancy and describes the complex and sad feelings she experienced during the six months after birth. In this study, the author looked at the mood changes that started before her pregnancy and continued in the postpartum period, and handled them autoethnographically. The author detailed the situation in terms of herself, his son and his husband by describing his experiences from prenatal period to the end of birth.

Phenomenon: I am an academic nurse working in the field of Obstetrics and Women's Health. In this true story, I have expressed my complex feelings at the end of my childbirth, my deep sorrow and my thoughts of death. Pregnancy is the world's most miraculous event for a woman diagnosed with infertility. The birth of the baby is the peak that crowns it. However, postpartum mood changes may undermine this magnificent ritual.

Having difficulty conceiving never occurs to a newly married individual but, sadly, you might experience it. When such a person suffers from postpartum depression as well, many people mistakenly believe that she is just a spoilt adult. When I conceived as a person diagnosed with infertility and gave birth to a healthy child, I thought life would be a bed of roses. From what I have experienced, I have discovered that one cannot fully understand what others experience without experiencing the same thing. It was very painful in my adventure to understand some things by personally experiencing them. I was having a difficult four-year infertility period. Hardly had I run out of hope with a premenopausal diagnosis when I ended up with a surprise pregnancy at the age of 42 . When I was 43 , I had my son born by cesarean section. Actually, everything seemed alright, but I was terrified; I was panicking; I could not sleep; and I was deeply unhappy. I had a deep sorrow combined with pain! I had fallen into a dark well and was constantly looking for a light, and a ladder to get out. I could not eat; I could not even drink water. I had a nipple fracture and mastitis. I had vaginal bleeding for six weeks after the delivery. My baby had diaper rashes and gained very little weight. I felt inadequate, unsuccessful and desperate. I couldn't look at myself in the mirror, nor did I look at my baby as he was mine. I was a mother aware of everything, but could not express it, constantly thinking of her own death, imagining herself at her own funeral, begging God and bargaining with him not to die until her little baby was 2 years old, 4 years old, 20 years old because she did not have the heart to leave him behind. I was very afraid of dying early, and I felt deep sorrow and pain thinking about death.

Discussion: When I examined ethnographic and autoethnographic articles, I found that there were many women who experienced similar feelings with me. Some women perceived motherhood as surreal and stated that they were shocked when they took their babies into their arms, that they had to be a perfect mother, that some women also had postpartum depression, that they questioned whether mothers who were diagnosed with infertility before were diagnosed with postpartum depression, and that they were sleepless, tired and unhappy. They stated that when she shared this situation with her husband, she did not understand herself and therefore kept her feelings to herself and gave up seeking help. Some of the expressions in the articles were "being seen as a normal but painful person, experiencing an anonymous chaos, struggling to find a way out, feeling alienated from everyday life, being unable to build attachment with your own baby and feeling as if you were holding someone else's baby, and being trapped". It is stated that postpartum mood changes in the mother negatively affect their husbands as well. According to a study, it was determined that there is a big change in the lives of the spouses of women with postpartum psychiatric disorders.

Conclussion and Suggestions: The postpartum period is very complex, emotionally very heavy and physically tiring. For this reason, this is the period when women need the most support. Although I knew that both physiological and psychological changes occur after the childbirth, I had forgotten everything. The verse of Ümit Yaşar Oğuzcan's famous poem "You have left me in a deep dark well without a ladder" can define the postpartum mothers very well. During this process, it is vital that health professionals take all pregnant women and postpartum mothers into consideration and monitor psychosocial health closely. 